\title{
ESTIMATION OF RESIDUAL STRESSES FOR MULTI-LAYER CIRCUMFERENTIAL WELDS OF OIL AND GAS PIPELINES
}

\author{
Andrii KYCHMA, Rostyslav PREDKO \\ Lviv Polytechnic National University, S. Bandery Str. 12, 79013 Lviv, Ukraine, \\ akychma@gmail.com, predko.rostuslav@gmail.com
}

\begin{abstract}
The article presents results of investigation of residual stresses for multi-layer circumferential welds of oil and gas pipelines. The research was carried out on a designed and manufactured testing equipment for the experimental determination of the stress state parameters in the zone of multi-layer welded joints of pipe segments with the external diameter of $1020 \mathrm{~mm}$ and the wall thicknesses of $9.5 \mathrm{~mm}$, of $14 \mathrm{~mm}$, and of 22 $\mathrm{mm}$ which were made of carbon steels of different quality (13G1S, 13G1SU, 17G1S and 17G1SU). Determination of residual stresses in the zone of multi-layered circumferential welds of pipe segments was carried out by means of the method by the electronic speckle-interferometry and by the method of magnetoelasticity. On the basic of analysis of the obtained graphic dependences, the recommendations for engineering practice are suggested.
\end{abstract}

Keywords: pipelines, circumferential welds, residual stresses, pressure reservoir, hydraulic testing

\section{INTRODUCTION}

The experience of long-term operation of pipelines and pressure vessels indicates the importance of taking into account the peculiarities of redistribution of their total residual stresses in the area of welds. The estimation of the residual technological stresses of the considered equipment must be carried out [1] by experimental, numerical and calculation methods. Gary S. Schajer [2] recommends for experimental determination of residual technological stresses such methods as ultrasonic, magnetic, X-ray diffraction, neutron diffraction, hole drilling, electronic speckleinterferometric methods, and others.

The results of investigations of the spatial distribution of residual stresses in the zone of welded joints of pipes using classical shell theory and the finite element method are given in [1]. Based on ABAQUS software and created 3-D and 2-D finite element models, [3] residual stresses in multi-layer welded joints of stainless steel pipes with an external diameter of $114.3 \mathrm{~mm}$ and a wall thickness of $6 \mathrm{~mm}$ were investigated. In the article [4] conclusions about the feasibility of using the 2D model in some cases instead of the 3D model were formulated. The transverse and longitudinal residual stresses in the welds of tees made of ASTM36 carbon steel were investigated using the ANSYS program [5]. Determination of residual stresses of multi-layer welds of large wall thickness shells $(50-110 \mathrm{~mm})$ of cylindrical vessels using FEM is considered in [6].

Residual stresses have a great influence on the strength of the material, on the stability of geometric sizes and configuration, as well as the on fatigue resource [2]. The paper [7] analyzes the process of relaxation of residual stresses in a weld joint under the influence of fatigue loading. Hobbacher A. F. [8] recommends to construct curves of fatigue of welded metal structures taking into account local stress concentrators due to the geometry of the weld and uneven residual stresses. Recently, method of speckle-interferometry for diagnostics of residual stresses of elements of longterm structures [9] is widely used. The method of determining the distribution of the stress state of main pipelines by a magneto-anisotropic method is considered in [10].

The residual stresses in a welded joint of two segments of pipes with the external diameter of $356.6 \mathrm{~mm}$ and the wall thickness of $19.1 \mathrm{~mm}$ which had been made of API 5L X65 steel were investigated by means of the method of neutron diffraction [11]. For this case, it has been shown that post weld heat treatment (PWHT) after welding reduces the axial residual stresses up to $20 \%$ of the yield strength of the base metal, and the circular residual stresses up to $30 \%$ of the yield strength of the metal weld. The work [12] investigated the distribution of residual stresses in the welds of pipes using neutron diffraction technique, finite element method (FEM), and strain gauge method. Based on comparison of the results of the research, the authors [12] suggested measures to improve the method of measuring the residual stresses in the welds of pipes by means of the method of neutron diffraction technology.

The results of investigations of residual stresses of butt-welded joints of pipes made of heterogeneous materials (stainless steel and carbon steel) are given in [13]. It has been shown that in the weld of 304 stainless steel and of A106 carbon steel pipes the maximum residual stresses tend to 
arise from the side of a stainless steel pipe, which causes an unbalanced distribution of residual stresses.

With the help of strain gauges [14], multi-layer joints of pipes with external diameter of $323.9 \mathrm{~mm}$ and wall thickness of $24.3 \mathrm{~mm}$ were investigated [14]. It has been established that in the strip specimen the residual stresses are compressive stresses in the facing layer of the weld and tensile stresses in the root weld. This indicates the effect of residual bending stresses that arose during the formation of the pipe from the sheet [2]. It was found in the paper [15] that for the girth weld of two segments of the pipes the value of the circular residual stresses essentially depends on the angle of the placement of the starting point of the welding referenced clock-wise arrow. Features of the distribution of residual stresses for "Short repair" and "Long repair" of girth welds for pipes of $316 \mathrm{H}$ stainless steel whose outside diameter is $432 \mathrm{~mm}$ and the wall thickness $19.6 \mathrm{~mm}$ are described in [16]. In the paper [17], the estimation of technical state of multi-layer welded joints of $10 \mathrm{G} 2 \mathrm{~S} 1$ steel of pipes whose external diameter is of $529 \mathrm{~mm}$ and wall thickness of $7 \mathrm{~mm}$ is considered. On the bases of fractographic features of the operational degradation of metal welded joints, reduction of the resistance of the grains themselves to brittle fracture is visualized.

The author of [18] investigated the effect of PWHT of V-shaped welded joints of A106-GRB steel pipes on the magnitude of axial and circular residual stresses. It has been experimentally established that after PWHT axial residual stresses almost vanish, and residual circular stress decrease to $60 \%$. The British Standard BS 7910 [19] provides for testing of welded tubular structures for leak proof test and strength under increased internal pressure or overload testing before starting to operate and after a certain period of operation, or under conditions of their repair or modernization. In [20], it is asserted that pressure test (such as a hydrotest or proof test) causes decrease technological residual stresses.

Theoretical foundations of the calculationexperimental method for determining the residual technological stresses in welds are considered in [21]. The peculiarities of the application of the calculation-experimental method for the determination of the stress-strain state of welded joints using the electromagnetic method are given in [22].

From the literature review, it is clear that the residual technological stresses of pipelines significantly affect the reliability of their welded joints and can lead to emergency situations. This problem is a very multi-factor problem, which depends on various parameters: type of welding, shape of the ends of the pipes, temperature regime of welding, standard quality of the material, electrodes, and others. In the literary review, different types of welded joints of pipes obtained by means of automatic welding or welding with rotating the welded joint are considered. Such a technology of welding various types of pipes ensures a constant value of the speed of the electrode movement and a stable useful net heat input.

This article investigates weld joints of pipes that are made using the technology used to replace a damaged section of a pipeline in a trench using manual welding without rotating the weld joint. This welding technology of pipe sections has a number of features and has been but insufficiently investigated. Therefore, the aim of this work is to study the residual stresses in the zones of multilayer welded joints of pipes whose external diameter is $1020 \mathrm{~mm}$, welded joints which are made in trench conditions without rotating the weld joint. Such a technology is widely used in the long-term operation of pipeline systems for the transportation of oil, gas, and other substances. We hope that the results presented by us will, to some extent, enrich the information on a better understanding of this urgent problem.

\section{EXPERIMENTAL EQUIPMENT}

The research was carried out on a designed and manufactured testing equipment for the experimental determination of the stress state parameters in the zone of multi-layer welded joints of pipeline segments (Fig. 1 - Fig. 3).

The basic diagram of the pressure reservoir of the testing equipment is shown in Fig.1. The testing equipment includes: a pressure reservoir made of five segments of pipes 1-5 (Fig. 1) whose external diameter is $1020 \mathrm{~mm}$ welded together, and two semi-spherical bottoms 6 being welded at the butts; pumping station 7; pressure gauge 8 ; storage tank 9 ; and ball valves $10-13$. The pressure reservoir was filled with water, and with the help of pumping station 7 it created internal pressure measured by the pressure gauge 8 (Fig.1).

The pumping station enables us to create a pressure in the pressure reservoir up to $15 \mathrm{MPa}$. According to the Instruction issued by Ukrtransgaz enterprise, before the operation, the pipeline with an outside diameter of $1020 \mathrm{~mm}$ is to be tested under a pressure of 7.5 MPa. The tests described in the article were performed with a maximum pressure of $6 \mathrm{MPa}$. Determination of the hoop and axial stresses in the segments of the pressure reservoir caused by the pressure was carried out by means of calculation and experimentally [23], using the device "MESTR-411".

The cylindrical segments of pipes 1-5 had been made of carbon steel of different qualities $13 \mathrm{G} 1 \mathrm{~S}$, $13 \mathrm{G} 1 \mathrm{SU}, 17 \mathrm{G} 1 \mathrm{~S}$, and $17 \mathrm{G} 1 \mathrm{SU}$; and the semispherical bottoms 6 had been made of 09G2S steel.

In this paper, we shall dwell on the study of multi-layer circumferential final welded joint 14, of segments of the pipes 4 and 5 of the pressure reservoir (Fig. 1), and of circumferential weld of individual experimental shell 15 (Fig. 2), geometric 
sizes and design of the ends of pipes are presented in Fig. 4.

The welding of the final joint 14 of the reservoir was performed at $\mathrm{t}=15{ }^{0} \mathrm{C}$, experimental test at $\mathrm{t}=21$ ${ }^{0} \mathrm{C}$. The segments of the pipe whose wall thickness are $9.5 \mathrm{~mm}$ were made of $13 \mathrm{G} 1 \mathrm{SU}$ steel, and

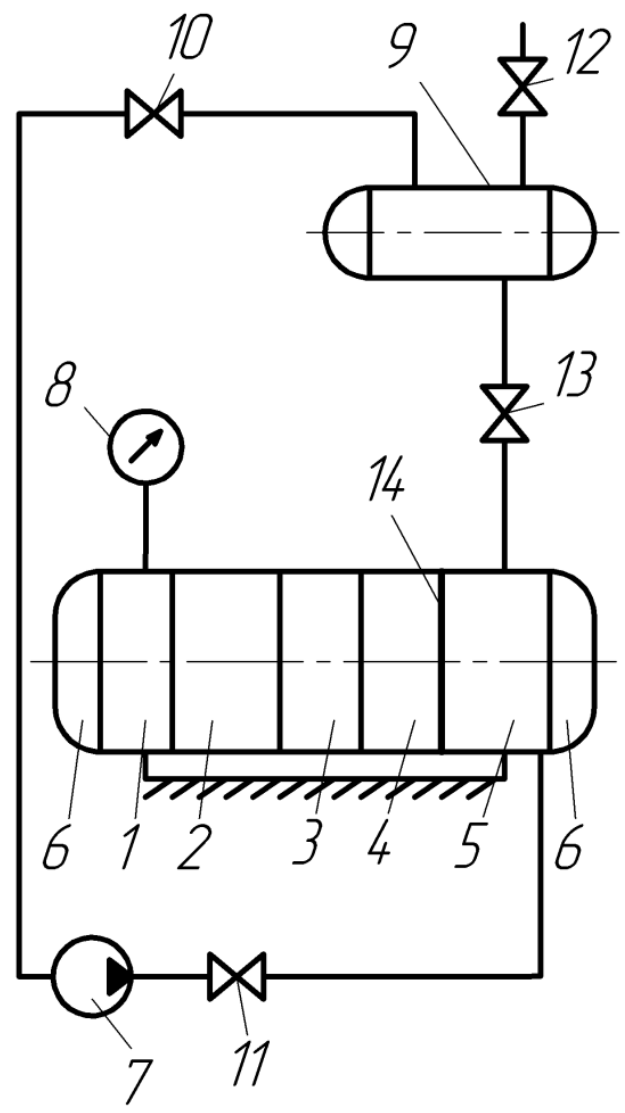

Fig. 1. Pressure reservoir of the testing equipment

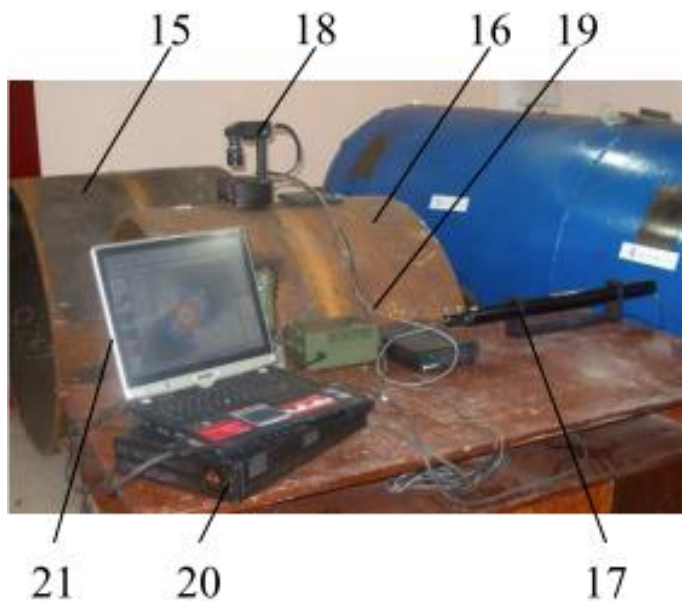

Fig. 2. Definition by method of electronic speckle-interferometry of residual stresses in zone of multi-layered circumferential welds of individual experimental shells made of two segments of pipes segments of pipe whose wall thickness are $14 \mathrm{~mm}$ were made of $17 \mathrm{G} 1 \mathrm{SU}$ steel. The weld of an individual experimental shell 16 had been made between two segments of pipes whose external diameter are $1020 \mathrm{~mm}$ and a wall thicknesses of 22 mm (Fig. 2). The segments, which had been made of different qualities steels (13G1SU and 17G1SU) were also investigated.

All welds under the investigation were made in three layers. The configuration of the ends of the segments of pipes 4 and 5 of pressure reservoir (Fig. 1) and the individual experimental shell 15 (Fig. 2) consisting of the two pipe segments with wall thicknesses of $9.5 \mathrm{~mm}$ and $14 \mathrm{~mm}$ are shown in Fig. 4.The ends of the pipe segments of the individual experimental shell 16 (Fig. 2) have been made of pipe segments of the same thicknesses of $22 \mathrm{~mm}$, and their ends have been made with a symmetrical configuration. The configuration of the ends of the welded pipe segments, the required number of layers, the type and size of the electrodes and welding modes are selected according to the Instruction issued by Ukrtransgaz enterprise concerning pipe welding under field conditions.

The chemical composition of the material of the used segments of pipes is given in Table 1, and their mechanical characteristics in Table 2.

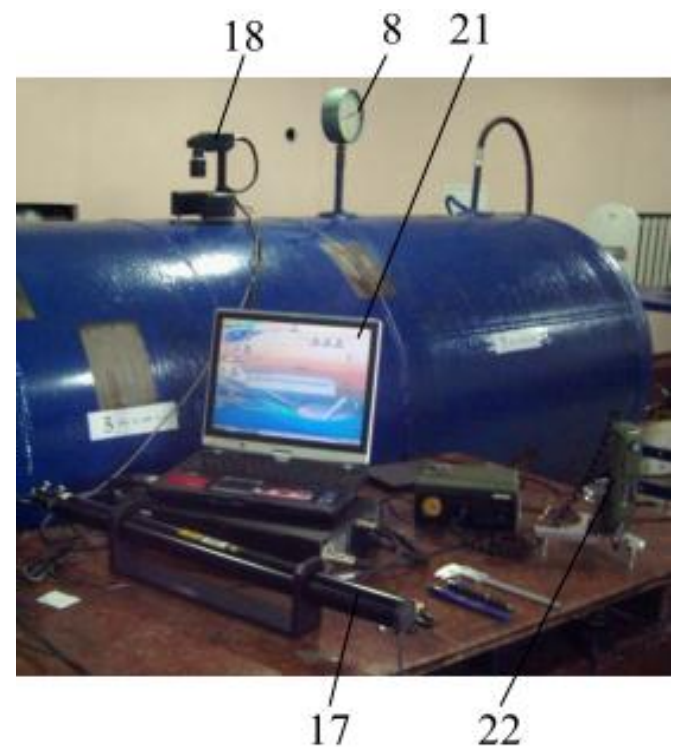

Fig. 3. Determination of residual stresses in zone of multi-layer circumferential weld of segments of pipes of pressure reservoir by method of electronic speckle-interferometry

Welding regimes of the manufacturing of multilayered welded joints of pipe segments of the pressure reservoir and individual experimental shells are given in Table 3. The multi-layered circumferential welds were manufactured according to the technology used in field conditions during the implementation of the mounting welds without rotating the connecting segments of pipes. 


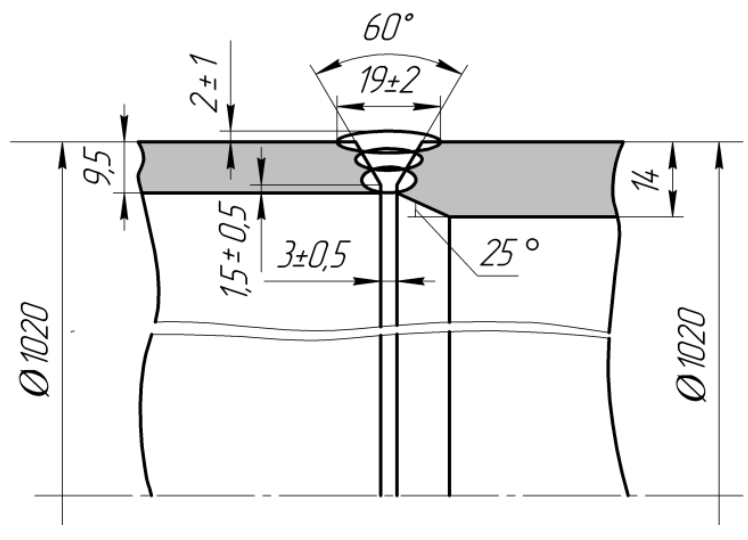

Fig. 4. Multi-layer circumferential welded joints of pipe segments

The multi-layer mounting welds were manufactured by means of UONI - 13/55P electrodes in threelayer: for the 1 st layer $\mathrm{I}=90 \ldots 130$ A the diameter of the electrode $3.2 \mathrm{~mm}$; for the $2 \mathrm{nd}$ and $3 \mathrm{rd}$ layers $\mathrm{I}=130 \ldots 210 \mathrm{~A}$, electrode diameter $4.0 \mathrm{~mm}$. The resulting multi-layer mounting welds were thus not subjected to additional treatment. The quality verification of all multi-layer welded joints was conducted by external examination, by means of Xray and ultrasonic detection. Deviations from Standards PN-EN ISO 6520-1 and PN-EN ISO 17637 were not detected.

Table 1. Chemical composition of steel pipes

\begin{tabular}{|c|c|c|}
\hline \multirow{2}{*}{$\begin{array}{c}\text { Chemical } \\
\text { composition } \\
\%\end{array}$} & \multicolumn{2}{|c|}{ Quality of steel } \\
\cline { 2 - 3 } & $13 \mathrm{G} 1 \mathrm{~S}-\mathrm{U}$ & $17 \mathrm{G} 1 \mathrm{~S}-\mathrm{U}$ \\
\hline $\mathrm{C}$ & 0.13 & 0.19 \\
\hline $\mathrm{Mn}$ & 1.54 & 1.42 \\
\hline $\mathrm{Si}$ & 0.50 & 0.48 \\
\hline $\mathrm{Ti}$ & 0.022 & 0.024 \\
\hline $\mathrm{Al}$ & 0.041 & 0.045 \\
\hline $\mathrm{S}$ & 0.006 & 0.02 \\
\hline $\mathrm{P}$ & 0.022 & 0.017 \\
\hline $\mathrm{Cr}$ & 0.04 & 0.03 \\
\hline
\end{tabular}

Table 2. Mechanical characteristics of steel pipes

\begin{tabular}{|c|c|c|}
\hline \multirow{2}{*}{ Parameter } & \multicolumn{2}{|c|}{ Quality of steel } \\
\cline { 2 - 3 } & $13 \mathrm{G} 1 \mathrm{~S}-\mathrm{U}$ & $17 \mathrm{G} 1 \mathrm{~S}-\mathrm{U}$ \\
\hline $\begin{array}{c}\text { Ultimate strength } \\
\sigma_{\mathrm{B}}, \mathrm{MPa}\end{array}$ & 600 & 570 \\
\hline $\begin{array}{c}\text { Yield strength } \sigma_{\mathrm{T}}, \\
\mathrm{MPa}\end{array}$ & 420 & 390 \\
\hline Strain $\delta, \%$ & 26 & 27 \\
\hline $\begin{array}{c}\text { Impact toughness } \\
\mathrm{KCV}, \mathrm{J} / \mathrm{cm}^{2}\end{array}$ & 71 & 58 \\
\hline
\end{tabular}

Table 3. Welding regimes during non-rotating manufacturing of welded joints of segments of pipes

\begin{tabular}{|c|c|c|c|c|}
\hline $\begin{array}{l}\text { Layer } \\
\text { of } \\
\text { weld }\end{array}$ & $\begin{array}{c}\text { Welding } \\
\text { current } \\
\mathrm{I}_{\mathrm{c}}, \mathrm{A}\end{array}$ & $\begin{array}{l}\text { Voltage } \\
\text { on the } \\
\operatorname{arc} U_{a}, V\end{array}$ & $\begin{array}{l}\text { Diameter } \\
\text { of } \\
\text { electrodes } \\
\text { D mm }\end{array}$ & \multirow{4}{*}{$\begin{array}{c}\text { Quality of } \\
\text { electrodes } \\
\text { UONI- } \\
13 / 55 P\end{array}$} \\
\hline 1 & 100 & 22 & 3 & \\
\hline 2 & 150 & 20 & 4 & \\
\hline 3 & 150 & 20 & 4 & \\
\hline
\end{tabular}

\section{PROCEDURS AND RESULTS}

In pipelines with outside pipe diameters of 820$1420 \mathrm{~mm}$ and wall thicknesses of $8-30 \mathrm{~mm}$, the radial residual stresses in the weld zone are much less than the hoop and axial residual stresses. Thus, the determination of residual stresses in the weld areas of such pipelines can be performed using a two-dimensional model of shell theory.

Determination of hoop and axial residual stresses was carried out by fixing the change of two interferometric patterns in the direction along the axis of the pipeline segment (axial stresses) and in the direction perpendicular to the longitudinal axis of the pipeline segment (hoop stresses).

Determination of residual stresses in the zone of welds of individual experimental shells (Fig. 2) and in the zone of welds of segments of pipes of a pressure reservoir (Fig. 3) were carried out using the method of electronic speckle-interferometry. The basis of this method [24] is the ability of laser radiation to create a certain structure during reflection from the surface of the measuring. During displacement, which occurs due to deformation, for example, when drilling a $2 \mathrm{~mm}$ deep hole of $2 \mathrm{~mm}$ diameter, there emerges a change in speckle image. Using the information obtained, by means of a special software, the values of residual stresses at the selected points near the circumferential weld of the pipe segments were determined in the axial and the circular directions. The speckle-interferometry complex (Fig. 2 and Fig. 3) includes a laser 17, a compact speckleinterferometer with CCD-camera 18, optical fiber 19, optical signal transducer into digital signal 20, personal computer 21 , drill with drill-bench 22 . At a distance of $70 \mathrm{~mm}$ from the axis of the weld along a generative of the shell with a wall thickness $t=14$ $\mathrm{mm}$ (with a certain step) there were drilled nonthrough holes of a diameter of $\mathrm{d}=2 \mathrm{~mm}$ and a depth of $h^{*}=2 \mathrm{~mm}$. As a result of drilling a non-through hole, an elastic reduction of the residual stresses in the pipe segments occurs, which was recorded by two speckle-images.

Having taken into account these changes, the values of residual stresses at the control points in the zone of the circumferential weld of the pipe segments in the axial and the circular directions were calculated. The measurement was carried out symmetrically about the axis of the weld. The distances from the axis of the weld took the following values: $-70,-55,-40,-30,-20,-10,+$ $10,+20,+30,+40,+55,+70 \mathrm{~mm}$.

The averaged characteristics of the residual stresses in the area of the aforesaid multi-layer weld joint of the pressure reservoir were also determined by means of the method of magneto-elasticity (Fig. 5). Measuring tract (Fig. 5) included a stress gauge 23, a transducer type sensor 24, a bench 25 for mounting the sensor 24, and elastic elements 26 for fixing the bench 25 . The "MESTR-411" device was used according to the method suggested in [23] for determining the residual stresses in the welds of the 
pipelines. The results of this method for determining the residual stresses in the zone of welds [23] showed good convergence with the results of the determination of similar residual stresses using strain gauge method.

The obtained results of the study were processed using the calculation-experimental method [21], taking into account the refined methodology [25].

In Fig. 6 the graphical dependences of the hoop $\sigma_{1}$ (curve 1) and axial $\sigma_{2}$ (curve 2) residual stresses as a function of distance from the axis of the

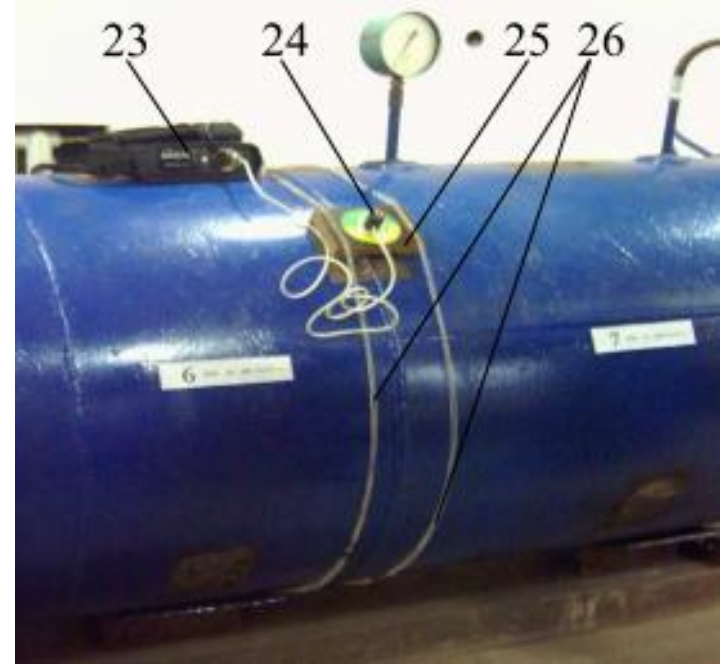

Fig. 5. Determination of residual stresses in the zone of multi-layer circumferential weld in segments of pipes of pressure reservoir by means of the method of magneto-elasticity

controlled multi-layer weld of individual experimental shell 15 at the outer surface of pipe segments with wall thicknesses of $9.5 \mathrm{~mm}$ and of $14 \mathrm{~mm}$ with external diameter of $1020 \mathrm{~mm}$ are shown; and in Fig. 7 that for equally-thick individual experimental shell 16 on the outer surface of pipe segments with a wall thickness of $22 \mathrm{~mm}$ and external diameter of $1020 \mathrm{~mm}$. Distribution of hoop residual stresses $\sigma_{1}$ and of axial residual stresses $\sigma_{2}$ on outer surface of multilayer the welding joints of individual experimental shells 15 and 16 which were determined by the speckle-interferometry method designated by curve- 1 and curve- 2 and results which were determined by calculation-experimental method using the magneto-elasticity method designated by squares and asterisks respectively (Fig. 6, Fig. 7).

To determine the influence of hydraulic testing of pipelines for residual stresses, the following experiment was conducted. Multi-layer final welded joint 14 (Fig. 1) of segments of pipes with outer diameter of $1020 \mathrm{~mm}$ and wall thicknesses of $9.5 \mathrm{~mm}$ and of $14 \mathrm{~mm}$ (Fig. 3 and Fig. 5), which were part of the pressure reservoir, were investigated. This distribution is presented for outer surface of welding different-thickness joint of the pressure reservoir. The segments of pipes were

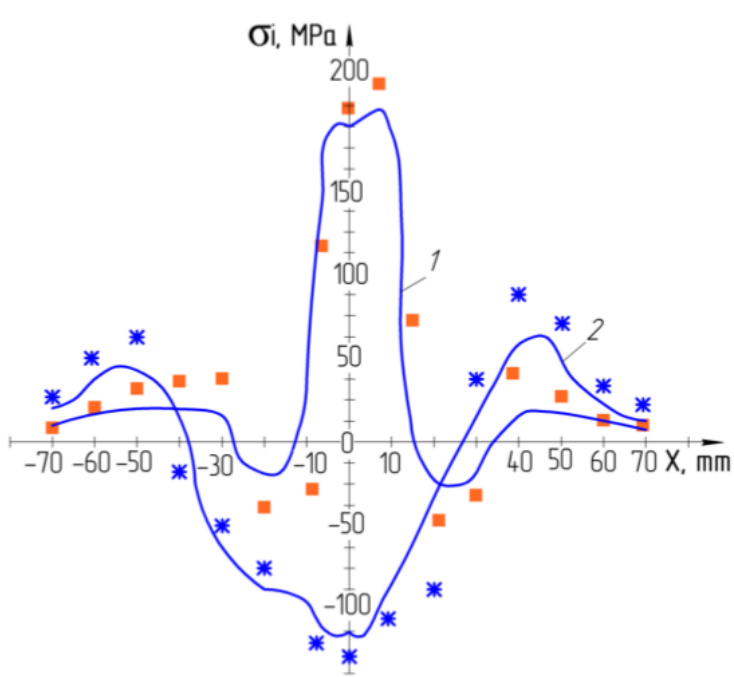

Fig. 6. Distribution of hoop residual stress $\sigma_{1}$ (curve-1) and of axial residual stress $\sigma_{2}$ (curve-2) in the outer surface of multi-layer the welding joint of individual experimental shell 15 (Fig. 2) as function of the distance from the weld axis (the curve on the graphs correspond to the experimental data which are determined by the speckle-interferometry method; designated by squares and asterisks respectively; the hoop and axial residual stresses obtained by calculationexperimental method using the magneto-elasticity method)

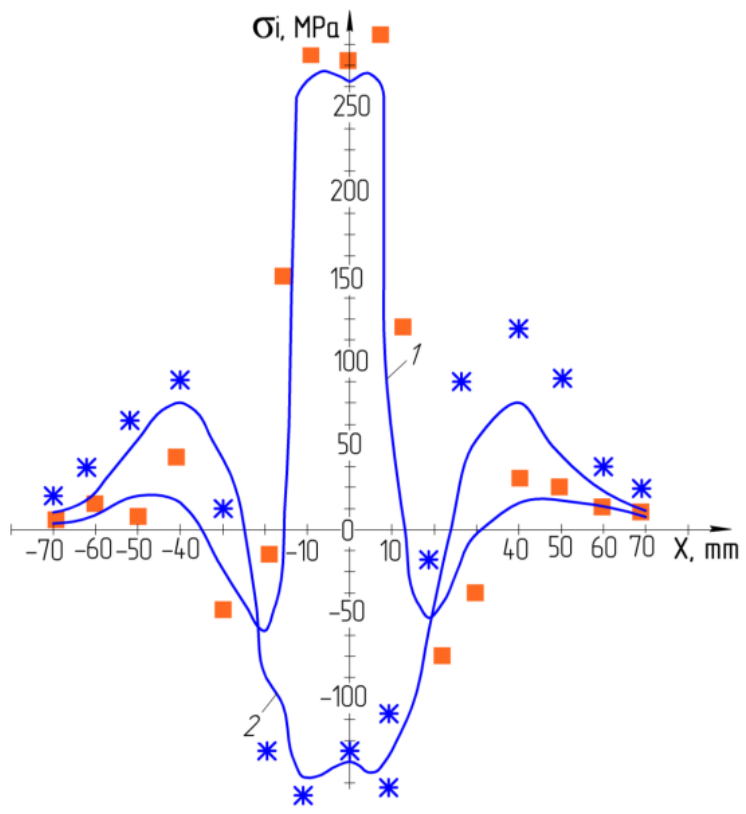

Fig. 7. Distribution of hoop residual stress $\sigma_{1}$ (curve-1) and axial residual stress $\sigma_{2}$ (curve-2) in the outer surface of the welding joints of segments pipes of the equal wall thickness individual experimental shell 16 (Fig. 2) as function of the distance from the weld axis (the other designations are the same as those in Fig.

6)

made of the 13G1SU steel and of 17G1SU steel, resptevily; the chemical composition and mechanical characteristics of them are given in Table. 1 and in Table. 2. Gas pipelines of these 
parameters are operated in Ukraine with a working pressure of 4.0...5.5 MPa. Hydraulic testing of the pressure reservoir was carried out at a pressure of 6.0 MPa. In Fig.8, the corresponding curves 1 and 3 , which represent the values of hoop and axial residual stresses in final welded joint of the pressure reservoir before hydraulic testing, and the curves 2 and 4 the values of hoop and axial residual stresses after hydraulic testing are presented.

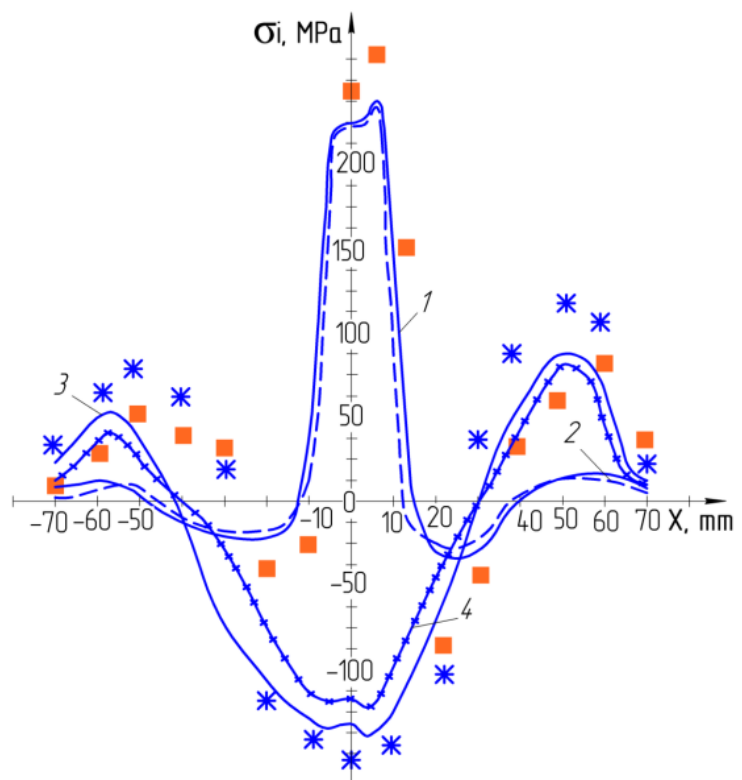

Fig. 8. Distribution of hoop residual stress $\sigma_{1}$ before conduct (curve-1) and after conduct (curve-2) of the hydrotest and that of axial residual stress $\sigma_{2}$ before conduct (curve-3) and after conduct (curve-4) of the hydrotest in outer surface of welding joints different-thickness

joints of the pressure reservoir as function of the distance from the weld axis (the other designations are the same as those in Fig. 6)

Distribution of hoop residual stresses and of axial residual stresses in the final welding joint on the pressure reservoir which were determined by calculation-experimental method using the magneto-elasticity method designated by squares and asterisks respectively (Fig. 8).

Graphic dependencies (Fig. 8) show that after hydraulic testing of pressure reservoir the hoop residual stresses $\sigma_{1}$ decreased by $5 \ldots 7 \%$. (curves 1 and 2 ), and axial $\sigma_{2}$ by $15 \ldots 20 \%$ (curves 3 and 4 ). Thus, for a new pipeline before commissioning or after major repairs, the leak proof test enables us to detect imperfections and partially reduce the residual technological stresses of the metal of the welds and the metal of the near-weld zone. In this case, in the segments of the pipe with a less wall thickness the reduction of axial residual stresses is greater.

In Fig. 6 - Fig. 8, values of hoop residual stresses $\sigma_{1}$ in the zone of welds which are determined using the calculation-experimental method are marked by squares; and the axial residual stresses $\sigma_{2}$ by asterisks. This distribution is presented for outer surface in multi-layer circumferential welding joint 14 of segments of the pipes 4 and 5 of the pressure reservoir (Fig. 1), and welding joints of individual experimental shell 15 and 16 (Fig. 2) as function of the distance from the weld axis.

From the comparison of graphic dependences in Fig. 6 and in Fig. 8, it follows that for identical geometric sizes and configurations of welded of pipe segments the axial residual stresses $\sigma_{2}$ in welded joints of these segments of pipes with fixed ends (Fig. 8) are higher than those in the case of free ends of pipes (Fig. 6).

Comparison of graphic dependencies 1-4 (Fig. 8) with corresponding values obtained by the calculation-experimental method confirms satisfactory qualitative and quantitative coincidence.

It is known that the rate of growth of fatigue cracks of pipeline segments in operational conditions depends on the stresses caused by the action of loads from the internal pressure and residual technological stresses. The residual stress component also influences the load cycle asymmetry coefficient. To evaluate the strength of a segments of a pipeline with crack-like defects, it is recommended to use the Failure Assessment Diagram (FAD) that allows two boundary states fragile and viscous - to be analyzed simultaneously.

\section{CONCLUSIONS}

- In the investigated multi-layer circumferential weld of two segments of pipes of a pressure reservoir with the wall thicknesses of $9.5 \mathrm{~mm}$ and of $14 \mathrm{~mm}$ (Fig. 8), there is a rather complicated stressed state. After hydraulic tests, the axial residual stresses $\sigma_{2}$ decreased by $15-20 \%$, and the hoop stresses $\sigma_{1}$ by 5-7 \%. For such a welded joint in a segment of pipe of less wall thickness, the decrease in axial residual stresses $\sigma_{2}$ is greater.

- Comparison of experimental dependences of hoop and axial residual stresses in the zone of welded joints obtained by speckle-interferometry with the corresponding values obtained by the calculation-experimental method with application of the method of magneto-elasticity (Fig.6 - Fig.8) confirms satisfactory convergence in both qualitative and quantitative aspects.

- Studies have shown that under the conditions which we had when manufactory the circumferential welds of two pipe segments with an external diameter of $1020 \mathrm{~mm}$ residual stresses can reach the value of (100-280) MPa. The value of the residual stresses obtained must be taken into account when determining the coefficients of the strength of the pipelines with crack-like defects during their long operation under conditions of nonstationary modes of loading (pipelines of compressor and pumping stations, steam pipelines of nuclear power plants). If necessary, measures to reduce the residual stresses must be undertaken. 


\section{REFERENCES}

1. Song S, Dong P, Zhang J. A full-field residual stress profile estimation scheme for pipe girth welds. Proceedings of the ASME 2012 Pressure Vessel \& Piping Division Conference PVP2012-78560. https://doi.org/10.1115/PVP2012-78560

2. Schajer GS. Practical residual stress measurement methods. First Edition. 2013.

3. Deng D, Murakawa H. Numerical simulation of temperature field and residual stress in multi-pass welds in stainless steel pipe and comparison with experimental measurements. Computational Material Science. 2006; 37(3): 269-277. https://doi.org/10.1016/j.commatsci.2005.07.007

4. Xu J, Jia X, Fan Y, Liu A, Zhang C. Residual stress analyses in a pipe welding simulation: $3 \mathrm{D}$ pipe versus axi-symmetric models. Procedia Materials Science. 2014; 3: 511-516.

https://doi.org/10.1016/j.mspro.2014.06.085

5. Safari H, Pourrajab R, Yaghootian A. Transverse and longitudinal stress analysis in reinforced welded oil branched pipes. MATEC Web of Conferences. 2018; 167: 02004.

https://doi.org/10.1051/matecconf/201816702004IC4 $\underline{\mathrm{M}}$

6. Wei RC, Xu SG, Wang C, Chen XD. Residual stresses in girth welded joint of layered-to-solid cylindrical vessels: a finite element model. Procedia Engineering. 2015; 130: 560-570. https://doi.org/10.1016/j.proeng.2015.12.267

7. Lu X, Hassan T. Residual stresses in butt and socket welded joints. Transactions, SMiRT 16, Washington DC, August 2001, Paper \# 1983.

8. Hobbacher AF. Recommendations for fatigue design of welded joints and components. Second Edition. 2016, 150 p. ISSN 2365-4368 https://doi.org/10.1007/978-3-319-23757-2

9. Lobanov LM, Pivtorak VA. Diagnostics of structures by the methods of electron shearography and speckleinterferometry. Materials Science. 2014; 49(4): 442448. https://doi.org/10.1007/s11003-014-9635-5

10. Minakov SM. Distribution of normal components of stressed state of the main pipelines by magnetic anisotropy method. Technical Diagnostics and Nondestructive Testing. 2011; 3: 23-27.

11. Ren Y, Paradowska A, Eren E, Wang B. Challenges of measuring residual stresses in large girth welded pipe spools by neutron diffraction. Materials Research Proceedings. 2016; 2: 575-580. http://dx.doi.org/10.21741/9781945291173-97

12. Maekawa A, Oumaya T, Noda M, Takahashi S, Saito T. Residual stress distribution in austenitic stainless steel pipe butt-welded joint measured by neutron diffraction technique. Materials Science Forum. 2010; 652: 116-122. https://doi.org/10.4028/www. scientific.net/MSF.652.116

13. Akbari D, Sattari-Far I. Effect of the welding heat input on residual stresses in butt-welds of dissimilar pipe joints. Journal of Pressure Vessels and Piping. 2009; 86(11): 769-776. https://doi.org/10.1016/j.ijpvp.2009.07.005

14. Mirzaee-Sisan A. Welding residual stresses in a strip of a pipe. International Journal of Pressure Vessels and Piping. 2018; 159: 28-34. https://doi.org/10.1016/j.ijpvp.2017.11.007

15. Dar NU, Qureshi EM, Hammouda MI. Analysis of weld-induced residual stresses and distortions in thinwalled cylinders. Journal of Mechanical Science and Technology. 2009; 23(4): 1118-1131. https://doi.org/10.1007/s12206-008-1012-6

16. Bouchard PJ, George D, Santisteban JR, Bruno G, Dutta M, Edwards L, Kingston E, Smith DJ. Measurement of the residual stresses in a stainless steel pipe girth weld containing long and short repairs. International Journal of Pressure Vessels and Piping. 2005; 82: 299-310.

https://doi.org/10.1016/j.ijpvp.2004.08.008

17. Krechkovs'ka H, Yanovs'ky S, Student O, Nykyforchyn H. Fractographic signs of the in-service degradation of welded joints of oil mains. Materials Science. 2015; 51 (2): 165-171.

18. Moradi M. Investigation of residual stresses on post weld heat treated A106-GRB steel pipe by holedrilling and FEM. International Journal of Mechanical Engineering and Robotics Research. 2017; 6(6): 519-523. https://doi.org/10.18178/ijmerr.6.6.519-523

19. BS 7910:2013+A1:2015. Guide to methods the acceptability of metallic structures. British Standards Institute, London, UK, 2015.

20. API 579-1/ASME FFS-1. Fitness-for service. The American Petroleum Institute, June, 2016, 1320

21. Osadchuk V, Banakhevych Yu, Ivanchuk O. Determination of the stressed state of main pipelines in the zones of circular welds. Materials Science. 2006; 42(2): 256-262.

22. Banachevych Yu, Dragilyev A. Design-experimental diagnostics of stress condition in the girth welded joints zone of pipelines by means of electromagnetic method. 37 International Conference Defektoskopie 2007. Prague, Czech republic. 2007: 11-16.

23. Dragilyev A, Banachevych Yu, Osadchuk V, Kychma A. Controlling and measuring equipment with dedicated software for diagnostics of pipeline sections near welding joints. Materials of the VII International Technical Conference."Risk management in pipeline operation". Plock, 2-3 June, 2005. 101-104.

24. Lobanov L, Pivtorak V, Savitsky V, Tkachuk G, Kiyanets I. Express control of quality and stressed state of welded structures using methods of electron shearography and speckle-interferometry. International Scientific-Technical and Production Journal Automatic Welding. 2005; 8: 35-40.

25. Kychma A. The method for determining the stressed state in girth welded joints of pipelines. Patent № 92921 Ukraine, 2014.

\section{Received 2019-06-20}

Accepted 2019-09-16

Available online 2019-09-17

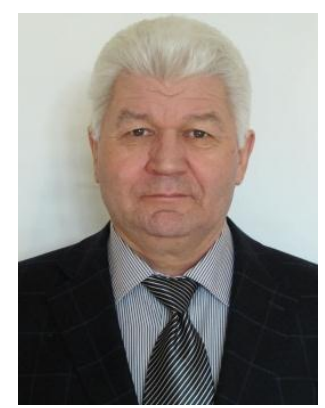

Andrii KYCHMA, Ph.D. works at Department of Technical Mechanics and Dynamics of Machines of Lviv Polytechnic National University, Ukraine. In scientific work conducts research is stress-strain state and monitoring of problematic segments of long-term pipelines taking into account the operational factors. The author of about 200 scientific papers, including 3 monographs and 40 patents. 


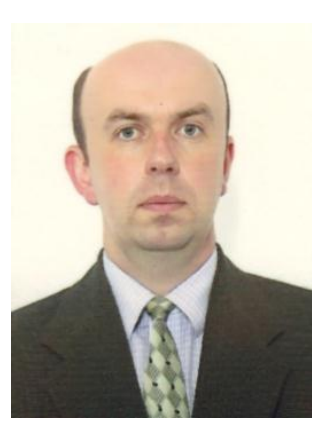

Rostyslav PREDKO, Ph.D. works at Department of

Technical Mechanics and Dynamics of Machines of Lviv Polytechnic National University, Ukraine. Scientific direction of research is connected with parametric synthesis of engineering structures. The author of about 50 scientific papers, including 6 patents. 